\title{
A especificidade de Quebec no quadro das Políticas Migratórias Canadenses
}

\author{
Marcus Vinicius Fraga* \\ Lucia Maria Machado Bógus**
}

A partir dos anos 1980, os fluxos emigratórios ganharam importância crescente e passaram a constituir um fenômeno demográfico relevante para o Brasil. A principal hipótese, no contexto de uma economia política das migrações (PATARRA; BAENINGER, 1996) é que a forma pela qual o fenômeno ocorreu no Brasil nos anos 1980 expressou, entre outros fatores:

a) o esgotamento das migrações internas como meio de acomodação das questões fundiárias não resolvidas, já que uma reforma agrária que objetivasse atender às reivindicações dos movimentos de luta pelo direito à utilização coletiva da terra, de fato não foi executada;

b) os anseios por maior mobilidade socioeconômica de segmentos populacionais residentes nas cidades. Neste caso, apesar dos avanços trazidos pela implementação de políticas de redistribuição de renda, como o programa Bolsa Família, as políticas públicas inclusivas não conseguiram superar o dilema da ampliação das desigualdades sociais;

c) a reconfiguração econômica do país frente a um capitalismo financeiro internacional que promoveu o surgimento de uma classe trabalhadora mundializada.

\footnotetext{
* Jornalista graduado pela Universidade Estadual de Londrina; especialista em politica e relações internacionais pela Fundação Escola de Sociologia e Política de São Paulo; mestrando em Ciências Sociais pela PUC/SP.

** Professora titular do Departamento de Sociologia e do Programa de Estudos Pós-Graduados em Ciências Sociais da PUC/SP. Coordenadora do Observatório das Metrópoles de São Paulo.
} 
O crescimento dos fluxos migratórios internacionais foi, por outro lado, favorecido tanto pelo desenvolvimento e barateamento dos custos de transporte, como pela diminuição do tempo de deslocamento e a maior segurança das viagens. Nos anos 1960, as teorias migratórias entendiam o fenômeno da atração de outros cidadãos como uma forma vantajosa de alguns países enfrentarem a queda na taxa de crescimento populacional. Naquele momento, presenciávamos um período de forte crescimento econômico das principais economias mundiais, aliado a um incentivo à imigração, o que favoreceu a formação de grandes fluxos migratórios e o estabelecimento de redes.

Após a crise energética em 1973, observou-se, no entanto, uma depressão econômica que trouxe mudanças conjunturais nas políticas migratórias até então adotadas pelas principais economias mundiais. A opinião pública de grande parte dos países desenvolvidos passou a se posicionar contrariamente ao ingresso de novos imigrantes, muitas vezes culpabilizados pela precarização das condições econômicas e sociais nas regiões de destino. 0 desgaste eleitoral dos políticos favoráveis ao livre fluxo de pessoas provocou uma mudança de posicionamento e o custo político-econômico levou ao estabelecimento das barreiras de entrada, que passaram a se chocar com os fluxos resultantes de redes migratórias já estabelecidas.

As fronteiras passaram então a funcionar mais incisivamente como barreiras tendo em vista evitar uma "enxurrada" de não-cidadãos nos principais países receptores. Conforme Zolberg, “(...) Dadas as disparidades entre os países do mundo, o estabelecimento de entradas livres causaria fluxos ilimitados, levando a uma drástica mudança que traria a equalização mundial, e, portanto, uma queda violenta nos níveis de emprego e consumo entre os países mais desenvolvidos" (ZOLBERG, 1989, p. 409, tradução nossa).

A transformação das fronteiras como mecanismo de controle dos acessos seguiu, a partir de então, um processo de judicialização da pertença, ou seja, a necessidade de possuir um status comprobatório frente ao Estado, e, as decisões legislativas, ancoradas na avaliação da opinião pública, passaram a embasar, cada vez mais, as políticas migratórias nos diferentes países do mundo.

Nas últimas décadas, as democracias capitalistas têm reafirmado as suas políticas de imigração de longo prazo que, no geral, estabelecem barreiras contra a imigração, mas com pequenas portas de entrada que permitem fluxos específicos. Uma das portas foi criada para permitir a aquisição de certos tipos de fluxos e outra para ingresso de um pequeno número de asilados. As características das migrações internacionais dependem em grande medida de como essas aberturas são definidas (ZOLBERG, 1989, p. 406, tradução nossa).

Este artigo pretende discutir, a partir do estudo de um caso concreto, em que medida as fronteiras e as políticas de ingresso podem gerar fortes 
externalidades econômicas, políticas e sociais. Para isso, nos propomos fazer uma análise da política de imigração de Quebec e de suas consequências para o imaginário e as expectativas migratórias dos alunos de uma escola de língua francesa quebequense em São Paulo, com forte apelo à emigração. Para realizar a primeira etapa da proposta, partimos dos trabalhos de alguns cientistas sociais canadenses buscando perceber como eles abordam o fenômeno das migrações para o Canadá e sua relação com as políticas públicas do governo da província franco-canadense de Quebec. Na segunda etapa, realizamos um levantamento com estudantes de francês dessa escola de língua francesa, por meio da aplicação de um breve questionário socioeconômico.

\section{O contexto de Quebec na política canadense de imigração}

O Canadá foi o primeiro país do mundo a adotar, em 1971, o multiculturalismo como uma política de Estado (CAMERON, 2004). Ao longo de sua história, o país prosperou baseado na diversidade e em uma coexistência pacífica entre seus cidadãos de diversas procedências. Esta diversidade foi o produto de decisões racionais tomadas por seus habitantes e dirigentes, os quais, em sua maioria, consideram a imigração e a diversidade de etnias um orgulho nacional.

$\mathrm{Na}$ história canadense, a imigração está associada à construção de uma nação e, mais especificamente, ao desenvolvimento de uma economia robusta enraizada em um vasto território. Este ímpeto por desenvolver o país levou à construção de um modelo de imigração de larga escala ao longo de todo o século XX. A intenção de atrair um grande contingente populacional baseava-se, sobretudo, na necessidade de constituir um mercado interno forte que pudesse absorver a produção industrial canadense (CAMERON, 2004).

Atualmente, com a aceleração das trocas e a ampliação do comércio ultramarino, essa necessidade premente de criação de um grande mercado interno, não se coloca com a mesma importância, o que produziu uma alteração significativa na política de imigração canadense, hoje mais focada na atração de imigrantes qualificados, que supram a demanda em atividades carentes de mão de obra naquele país (BILES; BURSTEIN; FRIDERES, 2008b).

Por outrolado, os requisitos do mercado de trabalho têm se mostrado cada vez mais complexos provocando um aumento dos custos de treinamento e ampliando os problemas de integração dos imigrantes. "(...) as contínuas dificuldades dos imigrantes em ter o reconhecimento de suas habilidades educacionais e laborais adquiridas antes da entrada sugerem que, sem estratégias robustas de integração objetivando reduzir as barreiras, os programas de imigração vão continuar a se debaterem" (BILES; BURSTEIN; FRIDERES, 2008a, p. 8, tradução nossa).

Além disso, há um consenso entre os pesquisadores canadenses de que hoje em dia o poder de comunicação nas línguas oficiais do país constitui uma barreira que o imigrante precisa superar para conseguir se inserir no mercado de trabalho: somente com os conhecimentos linguísticos é que um imigrante 
altamente qualificado conseguirá traduzir para o seu dia a dia os conhecimentos que já possui em sua língua materna (BILES; BURSTEIN; FRIDERES, 2008b).

De uma maneira geral, o aumento de oportunidades de trabalho, decorrente daglobalização, os tratados de livre comércio (NAFTA) e a competição internacional são fatores que ampliam as dificuldades para atrair imigrantes qualificados. É por isso que o Canadá se apresenta ao mundo destacando suas vantagens comparativas em relação a outros destinos - como um país que possui uma excelente infraestrutura física, boas estradas, aeroportos, ferrovias; excelente ambiente intelectual, com universidades internacionalmente reconhecidas; um ensino fundamental e médio gratuito, bilíngue e de qualidade, e com um sistema de saúde modelo. Isso tudo em uma atmosfera de paz e tolerância social.

A diversidade étnica e cultural é considerada no Canadá o instrumento de criação de um círculo virtuoso sustentado pela imigração de trabalhadores qualificados e por uma rede de suporte social. Esta rede baseia-se na oferta de escolas, hospitais, e empregos ao imigrante, ao mesmo tempo em que entidades civis do terceiro setor e os governos (federal, provinciais e municipais) trabalham para criar um ambiente atrativo e acolhedor.

Entretanto, um desafio a ser enfrentado ainda pelo Canadá diz respeito à taxa de retorno aos países de origem ou mesmo de reemigração para outros países, de contingentes expressivos de imigrantes permanentes. Mais de $1 / 3$ dos homens imigrantes em idade de trabalho deixam o país em até 20 anos após a chegada. Mas o dado que chama mais a atenção é que aproximadamente $60 \%$ dos que deixam o país o fazem ainda no primeiro ano após a entrada. Por um lado, pode-se deduzir que a existência dessa taxa de retorno poderia significar que o mercado de trabalho canadense não está oferecendo os ganhos que os imigrantes esperavam auferir. Por outro, as dimensões de ordem cultural, emocional e geográfica, por exemplo, tornam a questão muito complexa, dificultando a clareza analítica a respeito dos fatores motivacionais desse retorno (SWEETMAN; WARMAN, 2008).

Do ponto de vista econômico, a imigração contribui para elevar o Produto Interno Bruto do Canadá. Mas, isso não significa que se eleve o PIB per capita. As pesquisas econômicas conduzidas sobre o tópico da imigração divergem sobre se o impacto da política imigratória é positivo ou negativo. Mas, todas chegam à conclusão de que, mesmo que o impacto seja positivo ele tem sido pequeno, pois a quantidade de imigrantes que entram por ano no Canadá é muito pequena para gerar consequências deletérias na estabilidade do modelo político e econômico adotado pelo país (SWEETMAN; WARMAN, 2008).

A política de imigração é concebida como política pública visando amenizar alguns problemas decorrentes da base demográfica do Canadá, sem, no entanto, resolvê-los. Sua efetividade se ancora em quatro pontos importantes:

- primeiro, ajuda a combater o custo da geração baby boomer (os nascidos após a Segunda Guerra Mundial até meados dos anos 1960). Como outros países desenvolvidos, o Canadá presenciou um crescimento $18 \%$ acima do esperado 
nos nascimentos entre 1945 e 1960. Esta geração está se aposentando e gerando custos para a previdência social do país (SWEETMAN; WARMAN, 2008);

- segundo, beneficia-se ao atrair imigrantes qualificados que não são produzidos pelo sistema educacional canadense. É importante salientar que um imigrante qualificado representa um custo muito baixo para o país que o recebe, pois sua trajetória profissional não foi custeada pelo país receptor;

- terceiro, como os imigrantes geralmente não rompem totalmente a relação com o país de origem, isso amplia as perspectivas de relações econômicas que podem incrementar as exportações;

- quarto e último, a economia do país se beneficia ao receber o capital e/ ou o espírito empreendedor dos imigrantes que chegam com a perspectiva de se estabelecer.

A opinião pública canadense aprova a política de imigração do país (JEDWAB, 2008). Pesquisas conduzidas pelo governo mostram que mesmo durante os ataques de 11 de Setembro, nos Estados Unidos (o momento de maior tensão na relação com os imigrantes), a popularidade da política de imigração do país se manteve estável. A porcentagem de nascidos no Canadá que acreditam que o número de imigrantes que entram no país, a cada ano, é pequeno ou adequado nunca foi menor que $60 \%$, nem mesmo durante os ataques terroristas às torres gêmeas do World Trade Center, em Nova lorque. Nos últimos anos, esse dado se manteve inalterado. Assim, "Os canadenses parecem ser mais propensos a concordar que os imigrantes têm uma influência positiva do que os cidadãos da maioria dos outros países receptores" (JEDWAB, 2008, p. 221, tradução nossa).

O Canadá é uma democracia federativa multicultural no sentido de que valoriza a diversidade étnica como uma bandeira da nação. Quebec é vista pelos pesquisadores canadenses como um ponto de análise essencial para compreender o que significa "ser canadense". O nacionalismo de Quebec é algo levado extremamente a sério no Canadá, sendo parte principal do que levou à formação de uma política multicultural no país. Muitas das demandas pela autonomia política de Quebec persistem desde a fundação do país e são caracterizadas pelos partidários de Quebec como uma espécie de consenso enquanto objetivo de luta política.

No caso do Canadá, a falta de uma identidade nacional unificadora possivelmente gerada pela diversidade linguística estabelecida territorialmente - gera questionamentos quanto à legitimidade do poder federal e perpetua uma luta por reconhecimento constitucional por parte de Quebec. Por não existir uma unidade étnica, os conflitos no modelo canadense de federalismo fugiram da tradicional disputa legalista de equilíbrio de poder, como a que se configurou nos Estados Unidos (GAGNON; IACOVINO, 2007).

Conforme Gagnon e lacovino (2007), os modelos "puros" de federalismo estadunidense e alemão foram criados para limitar os excessos do poder executivo. No Canadá, o modelo foi criado para acomodar a diversidade de nacionalidades. Ao longo da constituição histórica de Quebec, a província constitui um ponto 
de resistência cultural francesa e reivindica autonomia política e econômica. Na primeira conferência interprovincial, em 1887, ficou claro aos habitantes de Quebec que a noção de construção de um país fundado no dualismo cultural (uma parte francesa e outra inglesa) e na sua coexistência, dificilmente seria respeitada. Até porque as outras províncias utilizavam a doutrina do dualismo para restringir o acesso à educação em língua francesa à minoria franco-canadense espalhada pelos territórios não quebequenses.

Nesse quadro, a província franco-canadense passou a se considerar como um gueto de resistência, onde poderia ser assegurada a representação institucional à maioria populacional francesa. A grande depressão dos anos 1930 favoreceu o surgimento de reivindicações e consentimentos pela centralização da política econômica e por um "New Deal" canadense orquestrado pelo poder federal e a ser executado em todo Canadá como a única salvação plausível.

Entretanto, politicamente, Quebec continuou firme em sua concepção do princípio federal do dualismo, que conserva até os dias de hoje. A Comissão Real de Inquérito sobre Problemas Constitucionais, de 1956, também conhecida como Comissão Tremblay, foi criada por Quebec e defendeu a continuação do respeito à divisão dos poderes do compromisso original dualista por conta da distinção das comunidades culturais que levaram à formação do federalismo canadense. Até então, as outras províncias rejeitavam que Quebec pudesse negociar diretamente com Ottawa (cidade capital e sede do governo central canadense) mais autonomia em um momento em que a intervenção do governo federal vinha crescendo rapidamente.

Duas visões dominantes em Quebec dividem a corrente principal de seus pensadores nacionalistas nos anos 1960 . A primeira enxerga que o federalismo assimétrico poderia adequadamente satisfazer às necessidades de estabilidade e união no Canadá sem sobrepujar a diversidade do país. Para isso, cinco prérequisitos deveriam ser respeitados em uma renovação constitucional:

1-o reconhecimento explícito em um preâmbulo da Constituição Canadense de que Quebec é uma sociedade distinta;

2 - a concessão de maior poder para Quebec executar as políticas públicas de imigração visando à administração do recrutamento e integração dos recémchegados;

3 - a participação de Quebec na nomeação de três membros da Suprema Corte de Justiça com especialização em civil Law (sistema jurídico no qual os tribunais fundamentam suas sentenças nas disposições de códigos e leis. Em oposição, o restante do Canadá adota o common Law, praticado por países anglo-saxões, no qual o costume prevalece sobre o direito escrito).

4 - limitações ao poder de gastos federais;

5 - o reconhecimento do direito de Quebec a vetar qualquer emenda constitucional que venha a afetá-la.

Os partidários da assimetria acreditavam que o modelo simétrico, até então vigente no Canadá, não poderia mais operar uma vez que os cidadãos e os 
governos das províncias do restante do país olhavam para o governo federal e o "enxergavam" como o governo nacional, dotado de um instrumento principal de crescimento, enquanto este não era o caso dos cidadãos de Quebec.

A segunda visão entre os nacionalistas quebequenses era a de que o experimento federal havia falhado e que Quebec só conseguiria realizar seu projeto a partir de um rompimento com o restante do Canadá. Como decorrência, um novo acordo entre Quebec e o Canadá estaria fora da instância do federalismo. Esta visão acreditava ser possível estabelecer dois países distintos que mantivessem formalidade e proximidade econômica (GAGNON; IACOVINO, 2007).

Essas duas propostas foram apresentadas no âmbito das negociações Meech Lake - nos anos 1980 - que pretendiam elaborar uma nova Constituição. Como ambas recomendações quebequenses não foram acatadas na ratificação do acordo, Quebec se recusou a assinar a decisão. A partir daí, surgiu a Comissão sobre a Política e o Futuro de Quebec, estabelecida em setembro de 1990 pela Assembleia Nacional de Quebec. Os estudos da Comissão chegaram às mesmas conclusões elaboradas pelos partidários de Quebec no âmbito do acordo Meech Lake e foram publicados em 1991. Quebec não foi signatária do acordo Meech Lake, optando, assim, pelo rompimento com a federação, o que levou à realização de plebiscitos pela província a respeito da separação política (e não econômica) ou não do Canadá.

Nos últimos anos, todos os plebiscitos que ocorreram em Quebec apontaram para a existência de uma grande divisão na população entre aqueles que optam por uma independência e um rompimento unilateral, e os outros que acreditam que manter o atual status quo é a melhor alternativa para a província. $\mathrm{O}$ ano de 1995 é tido como o marco histórico no sentido de esfriar o sentimento nacionalista franco-canadense. Neste ano, um plebiscito indagando se Quebec deveria se separar do Canadá foi derrotado por uma margem muito estreita de 49,42\% "sim" para 50,58\% "não" (GAGNON; IACOVINO, 2007).

Antes desse momento histórico, no entanto, o governo federal já previa a possibilidade de rompimento como concreta e contava com apoio da população da província. Assim, numa tentativa de amenizar os ânimos, o governo federal e o de Quebec firmaram um acordo em 1991 (MINISTÈRE DES RELATIONS AVEC LES CITOYENS ET L'IMMIGRATION, 1991). Quebec negociou exaustivamente para conseguir autoridade para elaborar suas políticas migratórias. Estas são pensadas como corroboradoras da resistência cultural da nação baseada no fortalecimento e disseminação da utilização do francês. A preocupação dos cidadãos de Quebec tem por base o receio frente a um poder central que ao longo da história demonstrou claramente seus interesses em indexar Quebec não só territorialmente, mas, sobretudo, culturalmente.

A preservação da língua francesa é tida como o principal fator para o florescimento de uma identidade cultural quebequense. "A partir do declínio alarmante da taxa de natalidade em Quebec, o Estado passou a se preocupar 
com a tendência de seus habitantes aos poucos migrarem linguisticamente e se tornarem uma comunidade anglófona. Assim, a imigração e a integração tornaram-se interligadas ao destino da nação Quebec" (GAGNON; IACOVINO, 2007, p. 97, tradução nossa).

A valorização e exigência de que os imigrantes aprendam o francês se justifica por essa mesma lógica. O governo de Quebec investe em cursos de francês gratuitos para os imigrantes da província - após o processo de solicitação e aceite do visto permanente de imigração - objetivando uma completa articulação e integração dos mesmos à sociedade franco-canadense. Além disso, para atrair trabalhadores qualificados, o governo de Quebec estabeleceu escritórios de imigração voltados ao atendimento e ao recrutamento de imigrantes em todas as regiões do mundo: Magreb (em Montreal), Áustria (em Viena), Bélgica e França (em Paris), México (na Cidade do México), Síria (em Montreal), Hong Kong (na própria cidade), Canadá (em Montreal), e Brasil (em São Paulo). Através destes postos avançados de recrutamento, agentes de imigração do governo da província ministram palestras e fazem a primeira triagem dos candidatos. O público-alvo é formado por jovens de até 35 anos, casados ou não (ser casado atribui mais pontos), com filhos ou sem (ter filhos atribui mais pontos ainda), que tenham formação universitária e dois anos comprovados de atuação profissional na área de formação, nos últimos cinco anos precedentes à data de preenchimento do formulário de solicitação. É necessário que tenham pelo menos o nível intermediário de francês (quem sabe falar inglês também recebe mais pontos). Algumas profissões nas quais a província possui carência de mão de obra - como enfermagem, análise de sistemas, engenharias, etc., - possuem uma tramitação do visto de imigrante permanente mais acelerada e dessa forma os solicitantes com pouco esforço são aceitos. Com essas informações, é montado um ranking objetivo de recrutamento ${ }^{1}$.

Os imigrantes constituem, hoje, aproximadamente $10 \%$ da população de Quebec. Minorias visíveis são quase $50 \%$ dos imigrantes que desembarcam na província a cada ano. A perspectiva é de que até 2017 aproximadamente $20 \%$ da população do Canadá seja formada por minorias visíveis. Quebec recebe a cada ano por volta de 50 mil imigrantes (o Canadá inteiro recebe aproximadamente 225 mil). Outra característica que precisa ser mencionada é a alteração da composição dos países de origem dos imigrantes. Até a década de 1970, a maior parte deles era de origem europeia. Hoje o que vemos é uma diminuição da porcentagem de participação dos imigrantes europeus e um aumento de asiáticos, dos oriundos do continente americano - latino-americanos, principalmente - e africanos, os quais já contam mais da metade (CONSEIL DES RELATIONS INTERCULTURELLES, 2008).

Ser um imigrante em Quebec representa aceitar e adotar os preceitos de valorização da identidade da nação francófona. Desde que respeitem a lei, os imigrantes podem manter seus costumes e cultura, dieta, vestimenta, preferências sexuais e celebrações. Isto porque é a língua francesa que mantém em Quebec a base de uma sociedade coesa. 
Com essa perspectiva em mente, torna-se economicamente interessante o empreendimento de uma escola de língua francesa quebequense em São Paulo. Atraídos pela proposta de aprender o francês com o sotaque e meandros culturais do local para onde pretendem emigrar, jovens adultos que se encaixam no perfil buscado pela política imigratória de Quebec passam a buscar o conhecimento linguístico que Ihes falta para superar a barreira de acesso tanto ao visto de residente permanente como ao mercado de trabalho canadense, assim que chegarem à província. Na sequência, detalharemos melhor esse fenômeno.

\section{Os estudantes e o projeto migratório}

Fundada em 2006 pela franco-canadense Catherine Potvin, a École Québec é uma escola especializada no ensino do francês para as pessoas que desejam emigrar para Quebec. Além do ensino da língua, aspectos culturais da província canadense são apresentados aos estudantes. A escola funciona como um primeiro contato do provável futuro imigrante com a cultura quebequense e foi criada por iniciativa pessoal de sua proprietária.

O estabelecimento desta "rede migratória" iniciou-se quando Potvin, administradora de empresas com mestrado, vislumbrou a oportunidade de abrir seu próprio empreendimento. A escola não possui qualquer vínculo com o escritório do governo de Quebec, em São Paulo, e recebe aproximadamente cem estudantes por ano, sendo que desde sua fundação Potvin acredita que por volta de duzentos de seus alunos emigraram (aproximadamente $35 \%$ do total dos matriculados no período de 2006 a 2011); percentual bastante elevado, mas que também indica que a maioria dos ex-alunos não migrou para Quebec.

Visitamos a École Québec nos dias sete, oito e onze de junho de 2011. Realizamos, primeiramente, uma entrevista com a proprietária do estabelecimento no dia sete e iniciamos a distribuição dos questionários socioeconômicos, após o consentimento da mesma. Foram preenchidos 48 questionários, correspondendo à quase totalidade dos estudantes matriculados na ocasião, que concordaram em participar do levantamento. Cada questionário continha 13 perguntas fechadas e duas abertas indagando: 1- quais os motivos que o(a) levaram a buscar meios para emigrar do Brasil? 2- quais os motivos que o(a) levaram a escolher Quebec como destino?

Sempre que entrávamos em sala de aula para solicitar o preenchimento dos questionários, informávamos que se tratava de uma pesquisa acadêmica, sobre o perfil socioeconômico dos brasileiros que buscam o processo de imigração para Quebec. Além disso, explicávamos que se tratava de uma coleta de dados anônima e, portanto, não era necessária a identificação dos informantes.

Ao longo da coleta dos dados, nos deparamos com dois estudantes equatorianos que imigraram para o Brasil e agora estão pensando em Quebec como um novo destino migratório. Resolvemos incluí-los já que se tratava de residentes permanentes no Brasil. 
Compuseram a amostra 28 homens e 20 mulheres - todos com idade superior a 22 anos - dos quais 39 se autodeclararam brancos, 5 se declararam pardos, 1 negro, 2 orientais-asiáticos, e outro não respondeu. Quanto ao nível de escolaridade, 26 possuem ensino superior completo, 15 possuem pós-graduação completa (incluindo especialização, mestrado ou doutorado), cinco possuem pós-graduação incompleta, um declarou ter ensino médio completo e outro não respondeu.

Quanto ao estado civil, 30 se declararam casados, 15 solteiros, 2 em união estável, 1 separado, e nenhum divorciado ou viúvo.

Para criar um padrão para a análise dos dados coletados, resolvemos separar os questionários em cinco grupos de idade: de 21 a 25 anos, de 26 a 30 anos, de 31 a 35 anos, mais que 36 anos, e um último grupo para aqueles que não responderam a idade. No primeiro grupo, havia 3 solteiros e 1 casado. No segundo, 5 solteiros e 10 casados. No terceiro, 2 solteiros e 14 casados. No quarto grupo, 2 solteiros, 4 casados, 1 separado, e 1 em união estável. Dos que não informaram idade 3 eram solteiros, 1 casado e 1 em união estável.

Em relação à presença de filhos, cabe informar que dos casados com idades entre 31 e 35 anos, três possuem um filho e um possui dois filhos. Dos solteiros entre 31 e 35 anos, um possui um filho. Dos mais velhos que 36 anos e casados, todos possuem filhos (sendo dois com um filho apenas, um com dois filhos e um com três filhos). Um dos que se declararam em união estável informou que tem um filho. Todos declaram pretender imigrar com suas proles para Quebec.

A grande maioria dos entrevistados (46) está inserida no mercado de trabalho e, dentre os empregados, 37 possuem vínculo empregatício formal (com carteira de trabalho assinada). Quanto às profissões, foram declaradas: analista de sistemas, analista programador, analista de comércio exterior, analista de controladoria, administrador de empresas, estatístico(a), engenheiro químico, engenheiro de qualidade, engenheiro civil, projetista eletrônico, engenheiro mecatrônico, engenheiro de alimentos, consultor de SAP (Systems Applications and Products.), programador(a) de computação, educador(a) físico(a), psicólogo, dentista, enfermeira, biomédico, designer gráfico, professor(a) universitário(a), consultor(a) de imóveis, médico, militar da marinha, e editor(a) de filmes.

O questionário também indagava sobre a renda familiar bruta (total de ganhos de todos os membros da família), dividida em cinco faixas, levando-se em conta que o salário mínimo no Brasil no mês de junho de 2011 era de $\mathrm{R} \$$ 545,00 (quinhentos e quarenta e cinco reais):

a) acima de 20 salários mínimos (superior a $R \$ 10.900,00$ );

b) entre 10 e 20 salários mínimos (entre $R \$ 5.450,00$ e $R \$ 10.900,00$ );

c) entre 4 e 10 salários mínimos (entre $R \$ 2.180,00$ e $R \$ 5.450,00$ );

d) entre 2 e 4 salários mínimos (entre $R \$ 1.090,00$ e $R \$ 2.180,00$ );

e) até 2 salários mínimos (até $R \$ 1.090,00$ ).

As respostas apontaram para um nível de rendimento familiar bastante satisfatório, indicando que a emigração viria atender além da expectativa de 
maiores salários, a busca de melhor qualidade de vida para a família, uma vez que 10 entrevistados responderam à alternativa "a"; 19 responderam " $b$ "; 14 responderam " $c$ "; 4 responderam " $d$ "; um entrevistado não respondeu e nenhum respondeu à alternativa " $\mathrm{e}$ ".

Quanto ao nível de conhecimento do idioma, todos que assinalaram as respostas (apenas um não respondeu) afirmaram possuir algum nível de conhecimento de francês e inglês. Dos que possuem nível básico de francês (30), cinco também têm o nível básico de inglês, 10 o nível intermediário, 10 o nível avançado e cinco o nível superior. Dos que possuem nível intermediário de francês (17), cinco também têm o nível básico de inglês, três o nível intermediário, cinco o nível avançado e quatro o nível superior.

No questionário aplicado, foram feitas duas perguntas discursivas para tentar identificar as razões subjetivas indicadas como motivos para deixar o Brasil e também os motivos para imigrar para Quebec. As falas apresentaram certa uniformidade em relação aos motivos para deixar o Brasil, destacando-se: a busca de melhor qualidade de vida, de mais segurança pública, a existência de menores problemas de mobilidade urbana, a oferta de serviços públicos de qualidade, o sistema de justiça mais equânime, a menor desigualdade social, a menor corrupção em diferentes esferas da sociedade, o maior reconhecimento profissional, etc. Quanto à escolha do destino destaca-se a aceitação do imigrante pela sociedade quebequense, a possibilidade de viver uma experiência de vida e de trabalho no exterior, um local com qualidade de vida para toda a família. Seguem abaixo algumas das manifestações dos entrevistados, referentes à intenção de emigrar.

1 - Razões para sair do Brasil:

- "Falta de respeito dos governantes para com o povo brasileiro";

- "Violência do Brasil, trânsito de São Paulo, a política brasileira (Tiririca na política ninguém merece). Isso incomoda. Emprego aqui tem, mas a insegurança de viver num país injusto e violento incomoda muito mais";

- "O preço que se paga pelos produtos no Brasil: aqui se tem muito imposto";

- "Corrupção, altos impostos, políticas públicas ineficazes, política externa do governo federal inadequada";

- "A busca por uma sociedade mais justa, onde você tem retorno dos impostos que paga, sem ter que pagar por isso duas vezes, como ocorre no Brasil. E você vê que nada vai mudar, porque a sociedade se acomodou";

- "As leis que não funcionam";

- "O transporte público de péssima qualidade";

- "Desrespeito no trânsito e prioridade dos automóveis";

- "Falta de política de preservação do meio ambiente"; 
- "Pessimismo em relação às condições econômicas e sociais do Brasil";

- "Os ricos são favorecidos";

- "Pouca valorização da carreira e do profissional. Salários baixos";

- "Tenho o sonho de ter uma família e aqui (no Brasil) isso não é viável. Estou desiludida com meu país, corrupção, violência, má educação da população, falta de respeito com o próximo".

2-Razões para emigrar para Quebec:

- "Poder dar mais liberdade para minha filha, estar numa cidade mais tranquila e ter mais qualidade de vida";

- "Quebec tem o Programa de imigração único no mundo (mais fácil e o apoio do governo do Quebec)";

- "A qualidade dos serviços públicos, a facilidade e as portas abertas para receber o imigrante qualificado me fez querer ir para Quebec";

- "Quebec possui todas as qualidades que buscamos para a manutenção estável de nossas vidas";

- "Facilidade de [obter] visto de trabalho";

- "Boas universidades";

- "Mesmo fuso horário do Brasil";

- "Não acho o francês uma língua difícil, dificuldade que eu tinha com o inglês";

- "Também porque vejo muito testemunho de brasileiros sobre as oportunidades que existem lá";

- "Viver em uma sociedade com valores que julgo serem importantes na formação de um filho";

- "Admiração pela sociedade de Quebec e sua cultura";

- "Possibilidade de imigrar e conseguir recolocação profissional em um nível equivalente, além de ser um povo mais receptivo a estrangeiros";

- "Um país com um Estado mais presente e menos corrupto";

- "O processo de imigração é bem visto pelo [povo] local, reduzindo o risco de preconceito";

- "A facilidade para imigrar. Quebec está dando oportunidade para imigrar legalmente";

- "Pode-se até ganhar menos lá, mas a vida é mais digna";

- "Garantia de um sistema de saúde eficiente";

- "O fato de a educação que será oferecida aos meus filhos será pública e de qualidade";

- "Preocupação com o meio ambiente";

- "O país precisa de enfermeiras";

- "Eu achei o processo [de imigração] claro e bem organizado. É uma província segura e com qualidade de vida";

- "O custo de vida não é tão alto e mesmo com o salário mínimo as pessoas conseguem sobreviver". 


\section{Considerações Finais}

O final da década de 2010 trouxe um sentimento renovado de autoconfiança e otimismo em relação ao Brasil; o sentimento de que o país finalmente poderá dar certo e atingir sua saga desenvolvimentista. Parece que a máxima de que os países em desenvolvimento não seriam capazes de oferecer emprego e poder de consumo (ver esse argumento em: ZOLBERG, 1989) para seus cidadãos cada vez menos se aplica ao Brasil. Entretanto, isso não parece ser suficiente para brasileiros (incluímos aqui os dois estudantes equatorianos) qualificados profissionalmente se "agarrarem" a esse sentimento ufanista de que "agora o Brasil vai dar certo". Por que mesmo com emprego e poder de consumo esses brasileiros buscam o processo de imigração para Quebec? Essa é uma pergunta que não tem apenas uma resposta e que demanda múltiplas hipóteses.

O discurso comum dos estudantes da École Québec expressa a desilusão com a qualidade dos serviços públicos e garantias sociais no Brasil - segurança, saúde, educação, desigualdade social, transporte público precário, corrupção política, etc., - uma espécie de insegurança quanto ao contrato social vigente na sociedade brasileira. A emigração aparece, assim, como uma tentativa de escapar desse desencanto. Observamos que esses brasileiros buscam ser tratados pelo Estado como cidadãos, conseguindo ter acesso a serviços públicos e ser respeitados pelo trabalho que realizam - eles alegam que não possuem o devido reconhecimento que reivindicam. O perfil sociodemográfico dos estudantes da École Québec mostra que eles se enquadram no modelo típico da pirâmide demográfica brasileira hoje, com o predomínio de jovens em plena fase produtiva e reprodutiva.

Percebemos que um dos principais objetivos de Quebec ao implementar restrições de entrada está em minimizar o crescimento de tensões sociais criadas pela presença de um grande número de imigrantes: em democracias liberais, geralmente as políticas públicas refletem interesses capitalistas.

Há fortes indícios de que o nível de escolaridade é um dos fatores diretamente ligados à forma como alguém aceita, ou não, os problemas da sociedade brasileira. Pertencer a uma sociedade é uma das necessidades fundamentais dos seres humanos. A falta desse sentimento pode trazer consequências físicas e psicológicas ao desenvolvimento do bem estar de um cidadão (DOVIDO et al., 2010).

Castles (2008) afirma que uma das ambivalências deste início de século XXI é ele comumente estar associado à fluidez e abertura proporcionadas pelas melhorias nas infraestruturas de transporte e comunicações, levando as pessoas a pensarem frequentemente na permeabilidade das fronteiras dos estados nacionais, ao mesmo tempo em que o aumento do fluxo migratório gera o comportamento contrário por parte dos países potencialmente receptores, que cada vez mais levantam muros para barrar o acesso dos indesejáveis. $O$ autor também mostra que grande parte do fluxo global deste século que se inicia deverá ter o sentido sul-norte. 
O recrutamento internacional de pessoas altamente qualificadas é considerado positivamente em praticamente todos os países, enquanto trabalhadores pouco qualificados são vistos como fora de propósito em um contexto de economia pós-industrial.

[...] Hoje em dia, o discurso político dominante é de que a migração é um problema que precisa ser corrigido através de políticas públicas apropriadas (CASTLES, 2008, p. 2, grifo do autor, tradução nossa).

A movimentação de imigrantes qualificados é comumente associada à mobilidade profissional. Outro ponto importante a ser ponderado em relação ao fenômeno das migrações é que o desenvolvimento dos países periféricos não tende a reduzir os fluxos de pessoas. Com menor disparidade social entre os países, o fluxo migratório com vistas à ascensão econômica e social tenderá a ser menor. Entretanto, a migração é um fenômeno multicausal e outras circunstâncias poderão se tornar alavancadoras dos fluxos. Afinal, "(...) a migração faz parte das relações sociais normais" (CASTLES, 2008, p. 4, tradução nossa).

O modelo neoclássico de análise da migração está baseado em numa relação de custos e perdas na qual o migrante avalia se, de acordo com seus critérios individuais, é mais vantajoso permanecer ou mudar. "De acordo com esse modelo analítico, a mera existência de disparidades econômicas entre determinadas áreas é suficiente para gerar fluxos migratórios" (CASTLES, 2008, p. 7, tradução nossa). Dessa forma, estes fluxos tenderiam a trazer, no médio prazo, um equilíbrio das desigualdades.

Consideramos que as políticas de imigração, assim como a adotada por Quebec, levam essa questão econômica em conta para a elaboração das barreiras de entrada, mas esta não é a única variável que deve ser levada em conta para a análise destas políticas, pois este modelo teórico falha em identificar outros fatores motivacionais. São eles: inter-relações entre os diferentes fluxos migratórios, as migrações forçadas, a importância da história individual e da bagagem cultural de cada indivíduo, a complexa natureza transnacional e em vários níveis da migração (econômica, política e geográfica, por exemplo), e, sobretudo, a importância das relações interpessoais que alteram profundamente sua dinâmica conforme bem demonstra a teoria das redes (CASTLES, 2008).

Nesse sentido, não podemos esquecer que a globalização afetou diretamente essa dinâmica ao gerar um intercâmbio cultural jamais experimentado até então na história da humanidade. A migração deve ser vista não apenas como uma consequência das transformações sociais, mas também como uma de suas causas. E, como não se trata de um problema local, mas, sim, transnacional, deve ser pensada globalmente. A migração, como nos alerta Bauman (2009), é uma das questões mais importantes da pós-modernidade. 


\section{Nota}

1 - Mais informações sobre o processo de recrutamento de imigrantes qualificados podem ser obtidas através do site <www.imigracao-quebec.ca $>$.

\section{Referências}

BAUMAN, Z. Vida líquida. Rio de Janeiro: Jorge Zahar Editor, 2009.

BILES, J. Integration policies in english-speaking Canada. In: BILES, J. et al., (eds.). Immigration and integration in Canada: in the twenty-first century. Kingston: School of Policy Studies Queens' University, 2008. p. 139-186.

BILES, J. et al. Introdution. In: BILES, J.; BURSTEIN, M; FRIDERES, J. (eds.). Immigration and integration in Canada: in the twenty-first century. Kingston: School of Policy Studies Queens' University, 2008a. p. 3-18.

BILES, J.; BURSTEIN, M; FRIDERES, J. (eds.). Immigration and integration in Canada: in the twenty-first century. Kingston: School of Policy Studies Queens' University, 2008b.

CAMERON, E. Multiculturalism \& immigration in Canada. (Ed.). Toronto: Canadian Scholars' Press Inc., 2004.

CASTLES, S. Understanding global migration: a social transformation perspective. Conference on Theories of Migration and Social Change. St Anne's College, Oxford. Session 1: theories of global mobility. Disponível em: <http://www.imi.ox.ac.uk/pdfs/stephencastles-understanding-global-migration>. Acesso em: 20 out. 2011.

CONSEIL DES RELATIONS INTERCULTURELLES. Integration policies in Quebec: a need to expand the structures? In: BILES, J. et al. (eds.). Immigration and integration in Canada: in the twenty-first century. Kingston: School of Policy Studies Queens' University, 2008. p. $187-210$.

DOVIDO, J. F. et al. Understanding bias toward latinos: discrimination, dimensions of difference, and experience of exclusion. Journal of Social Issues, v. 66, no 1, p. 59-78, 2010.

GAGNON, A-G; IACOVINO, R. Federalism, Citizenship, and Quebec: debating multinationalism. Toronto: University of Toronto Press, 2007.

JEDWAB, J. Receiving and giving: how does the canadian public feel about immigration and integration? In: BILES, J. et al. (eds.). Immigration and integration in Canada: in the twenty-first century. Kingston: School of Policy Studies Queens' University, 2008. p. 211-230.

MINISTÈRE DES RELATIONS AVEC LES CITOYENS ET L'IMMIGRATION. Canada-Quebec accord relating to immigration and temporary admission of aliens. [1991]. Disponível em: <http://www.micc.gouv.qc.ca/publications/pdf/Accord_canada_quebec_immigration_ anglais.pdf $>$. Acesso em: 20 set. 2010.

PATARRA, N.; BAENINGER, R. Migrações internacionais recentes: o caso do Brasil. In: PATARRA, N. (coord.). Emigração e imigração internacionais no Brasil contemporâneo. 2a ed., São Paulo: FNUAP, 1996.

SEETMAN, A; WARMAN, C. Integration, impact and responsibility: an economic perspective on canadian immigration policy. In: BILES, J. et al. (eds.). Immigration and integration in Canada: in the twenty-first century. Kingston: Queens' University School of Policy Studies, 2008. p. 19-44.

ZOLBERG, A. R. The next waves: migration theory for a changing world. International Migration Review, New York, v. 23, no 3, p. 403-430, autumn 1989. Disponível em: <http://www.jstor.org/stable/2546422>. Acesso em: 5 jul. 2006. 


\title{
RESUMO
}

O artigo oferece uma discussão introdutória sobre a política de imigração da província de Quebec, no Canadá, a partir da leitura de trabalhos de cientistas sociais canadenses e brasileiros e da legislação daquele país relativa ao assunto. Apresenta-se também como essa política de imigração vem incentivando estudantes de uma escola de língua francesa quebequense, em São Paulo, a buscarem o visto de residentes permanentes. Enfoca-se ainda alguns elementos do perfil socioeconômico desses estudantes. Como pontos de partida e de chegada, as migrações internacionais são tratadas como uma das questões mais importantes da atualidade.

Palavras-chave: Política de imigração; Quebec; migração internacional.

\begin{abstract}
The article makes an introductory discussion on Quebec's migration policy, in Canada, from the analysis of Canadian and Brazilian social scientist's works, as well as from the country's related legislation. We also present how this migration policy has given incentives to students of a Quebecois French language school in São Paulo in order to make them look for permanent resident visas. We also expose some elements of the students' socioeconomic profiles. We start from and arrive at the conclusion that the international migrations are one of the most important issues of the present world. (Tradução de Nina Maria Pinheiro de Britto).
\end{abstract}

Keywords: migrations policy; Quebec; international migration. 